\title{
PHENOLIC ACIDS IN GRAINS OF WILD-TYPE BARLEY AND PROANTHOCYANIDIN-FREE MUTANTS
}

\author{
by \\ BARBRO JENDE-STRID \\ Department of Physiology, Carlsberg Laboratory, \\ Gamle Carlsberg Vej 10, DK-2500 Copenhagen Valby
}

Keywords: Phenolic acids, flavonoids, ant mutants, HPLC, polyphenols

\begin{abstract}
The phenolic acid composition in grains of wild-type barley and proanthocyanidin-free mutants in different ant genes was studied. No qualititative differences were detected between ant mutants and their wild-types. Quantitative differences in phenolic acid content were small. The sum of the six most abundant phenolic acids varied between 5 and $12 \mathrm{mg} \cdot 100 \mathrm{~g}^{-1}$ of barley (dry weight). Compared to proanthocyanidins and catechin in wild-type barley, the amount of acetone extractable phenolic acids is small, and the presence of simple phenolic acids in proanthocyanidin-free mutants of the genes ant 17 and ant 18 cannot explain the high polyphenol values measured according to the method of Jerumanis in beers produced from these mutants. Tests according to Jerumanis of fractions obtained from hydrolysed barley grain extracts by HPLC, revealed that the highest polyphenol values were obtained in fractions containing compounds related to flavones. These compounds are more abundant in mutants of the genes ant 17 and 18 than in mutants of the gene ant 13 .
\end{abstract}

\section{INTRODUCTION}

Barley grains contain a diversity of phenolic compounds, but until now most studies of these substances have concentrated on the proanthocyanidins, because of their important role in the formation of beer haze $(2,6,11,14,18)$. Procyanidins and prodelphinidins, often referred to as polyphenols, were rather early recognized as major phenolic components of beer haze (16). The proanthocyanidins have been considered essential for beer flavour and taste (3), but in recent experiments trained taste panels have not been able to distinguish beer brewed with malt of proanthocyanidin-free mutants from proanthocyanidin containing reference beer $(5,7,8)$.

Polyphenol content in beer and wort is often determined according to the procedure of Jeru- manis (1), in which compounds having an o-diphenol structure give rise to a red-brown coloured complex with ferric ions in alkaline solution, but barley grains contain a number of phenolic compounds with other substitution patterns, which do not give a colour reaction under these conditions. In beers made from the proanthocyanidin-free mutants ant 17-105, ant 18-102 and ant 18-111 50-80\% of the compounds reacting with ferric ions in the reference beer are present, while beer brewed from ant 13-13 barley contains only $15 \%$ of these substances which obviously are neither proanthocyanidins nor catechins $(23,24)$.

Diallelic crosses have identified six ant genes in barley, which upon mutation can block the synthesis of catechin and proanthocyanidin

Abbreviations: $\mathrm{CMC}=$ carboxymethylcellulose; $\mathrm{DHQ}=$ dihydroquercetin; $\mathrm{EDTA}=$ ethylenediamine tetraacetate; $\mathrm{HPLC}=$ high performance liquid chromatography; TLC = thin layer chromatography. 


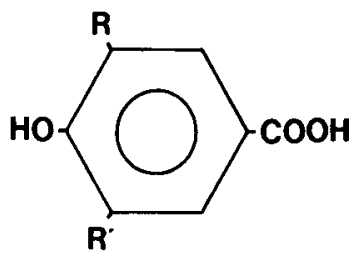

P-Hydroxybenzoic acid $R=R=H$

Protocatechuic acid $\quad \mathbf{R}=\mathbf{O H}, \mathbf{R}=\mathbf{H}$

Vanillic acid

$R=\mathrm{OCH}_{3}, \mathbf{R}^{\prime}=\mathrm{H}$

Gallic acid

$\mathbf{R}=\mathbf{R}=\mathbf{O H}$

Syringic acid

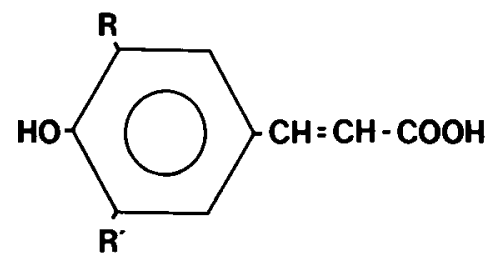

p-Coumaric acid $R=R^{\prime}=H$

Caffeic acid $\quad R=\mathbf{O H}, R^{\prime}=H$

Ferulic acid $\quad \mathrm{R}=\mathrm{OCH}_{3}, \mathbf{R}^{\prime}=\mathrm{H}$

Sinapic acid

$\mathbf{R}=\mathbf{R}^{\circ}=\mathrm{OCH}_{3}$

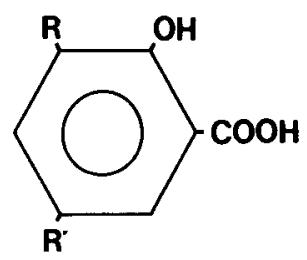

Gentisic acid

$\mathbf{R}^{\prime}=\mathbf{O H}, \mathbf{R}=\mathbf{H}$

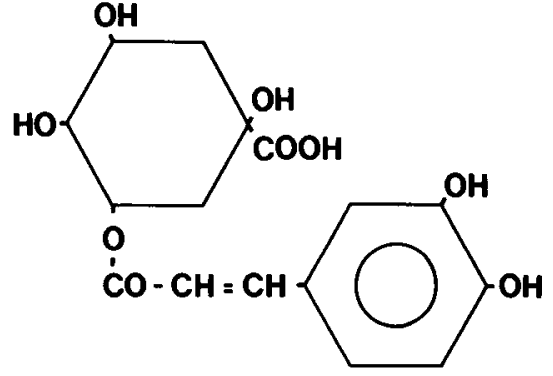

Chlorogenic acid

Figure 1. Structures of phenolic acids.

(12). Grains of wild-type barley as well as proanthocyanidin-free mutants in the different ant genes contain complex mixtures of phenolic compounds, such as phenolic acids and flavonoids. Mutants in the genes ant 17,18 and 22 accumulate intermediates in the biosynthetic pathway leading to the proanthocyanidins (15, 24).

Phenolic acids and flavonoids are widespread in the plant kingdom. Except for proanthocyanidins and catechins they seldom occur in free form but usually as glucosides or esters. The hydroxycinnamic acids are important precursors in the biosynthesis of flavonoids and lignins, and some of the phenolic carboxylic acids are present in lignin as esters (10). The chemical structures of different phenolic acids are shown in Figure 1.

In the present study, the phenolic acid composition in grains of proanthocyanidin-free mutants and their mother varieties was investigated as well as various intermediates and sideproducts of the flavonoid pathway. In order to find the explanation for the surprisingly high polyphenol values obtained with Jerumanis procedure on beers brewed from certain proanthocyanidin-free barley mutants, mutant and wild-type barley grain extracts were separated by high performance liquid chromatography (HPLC) and the fractions tested for their reaction with ferric ions in alkaline solution. 


\section{MATERIALS AND METHODS}

\subsection{Plant material}

Phenolic acids and flavonoids were analysed in grains of the three wild-type spring barley varieties Nordal, Triumph and Georgie, the anthocyanin-free spring barley variety Alva and the winter barley variety Tipper.

The following proanthocyanidin-free mutants were investigated: ant 13-13 (induced in Foma), ant 13-226 (induced in Secobra 18193), ant 13-101, ant 17-104, ant 17-142, ant 18-102, ant 18-141 (induced in Nordal), ant 13-152, ant 17-148 (= Galant), ant 17-151, ant 18-186 (induced in Triumph), ant 17-192, ant 18-196, ant 21-194 (induced in Georgie), ant 18-234 (induced in Tron), ant 19-109 (induced in Alf), ant 21-1507 (induced in Amagi-Nijo) and ant 221508 (induced in Haruna-Nijo).

\subsection{Chemicals}

All phenolic acid standards and (+)-catechin were obtained from Fluka AG (Buchs, Switzerland). Naringenin was from Sigma (St Louis, USA). Dihydroquercetin was purchased from Serva (Heidelberg, West Germany). Carboxymethylcellulose, sodium salt, low viscosity grade was obtained from BDH Chemicals Ltd (Poole, England).

\subsection{Extraction procedures}

Barley grains $(10 \mathrm{~g})$ were ground into a powder by a Brown Type Mx 32 homogenizer. The freshly ground flour was shaken with $100 \mathrm{ml}$ $75 \%(\mathrm{v} / \mathrm{v})$ acetone for $1 \mathrm{hr}$. The acetone was filtered off on a Büchner funnel and the barley flour reextracted twice. The extracts were com-

Table I

Average elution volumes with HPLC and $R_{r}$ values with TLC of phenolic acids and flavonoids. UV fluorescence after $\mathrm{NH}_{3}$ treatment and colours after spraying with ethanolic $\mathrm{FeCl}_{2}$ are also listed. (CAW = chloroform-acetic acid-water; BzAW = benzene-acetic acid-water).

\begin{tabular}{|c|c|c|c|c|c|c|}
\hline Compound & $\begin{array}{l}\text { Elution } \\
\text { volume } \\
(\mathrm{ml})\end{array}$ & CAW & $\begin{array}{l}R_{f} \text { value } \\
\text { BzAW }\end{array}$ & $\mathrm{CH}_{3} \mathrm{COOH}$ & $\begin{array}{l}\text { UV } \\
\text { fluorescence }\end{array}$ & $\begin{array}{l}\text { Colour with } \\
\text { ethanolic } \mathrm{FeCl}_{2}\end{array}$ \\
\hline gallic acid & 13.50 & 0.17 & 0.10 & 0.53 & purple & greyish black \\
\hline $\begin{array}{l}\text { protocatechuic } \\
\text { acid }\end{array}$ & 16.70 & 0.44 & 0.34 & 0.58 & purple & greyish black \\
\hline gentisic acid & 21.20 & 0.60 & 0.48 & 0.76 & turquoise & purple \\
\hline $\begin{array}{l}\text { p-hydroxybenzoic } \\
\text { acid }\end{array}$ & 21.20 & 0.77 & 0.74 & 0.71 & purple & orange \\
\hline $\begin{array}{l}\text { chlorogenic } \\
\text { acid }\end{array}$ & 22.70 & 0.20 & 0.03 & 0.72 & yellow-green & blue-grey \\
\hline vanillic acid & 24.30 & 0.89 & 0.89 & 0.68 & purple & brown \\
\hline caffeic acid & 25.60 & 0.48 & 0.32 & 0.34 & yellow-green & blue-grey \\
\hline syringic acid & 27.30 & 0.91 & 0.89 & 0.63 & purple & purple \\
\hline p-coumaric acid & 37.40 & 0.82 & 0.78 & 0.54 & purple & brownish orange \\
\hline ferulic acid & 42.40 & 0.90 & 0.89 & 0.50 & blue & greyish brown \\
\hline sinapic acid & 44.90 & 0.92 & 0.85 & 0.42 & turquoise & greyish purple \\
\hline o-coumaric acid & 47.40 & 0.85 & 0.79 & 0.58 & orange & yellow \\
\hline cinnamic acid & 58.40 & 0.94 & 0.96 & 0.64 & dark purple & bright yellow \\
\hline (+)-catechin & 17.20 & 0.11 & 0.05 & $0.5 !$ & dark purple & grey \\
\hline dihydroquercetin & 38.80 & 0.33 & 0.11 & 0.51 & greenish purple & greyish purple \\
\hline $\begin{array}{l}\text { naringenin } \\
\text { (standard) }\end{array}$ & 66.00 & 0.79 & 0.78 & 0.35 & purple & brownish pink \\
\hline $\begin{array}{l}\text { naringenin related } \\
\text { compound in ant } \\
17 \text { mutants }\end{array}$ & 66.00 & 0.89 & 0.88 & 0.35 & purple & brownish pink \\
\hline
\end{tabular}




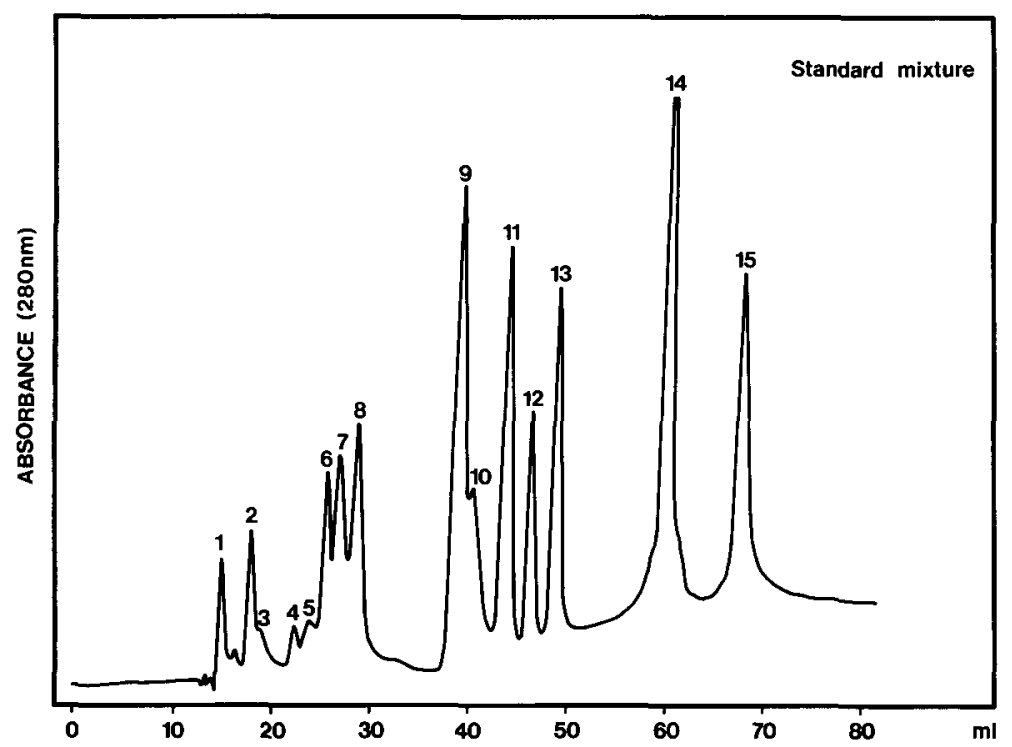

Figure 2. Chromatogram (HPLC) of 16 phenolic standards. 1. gallic acid, 2. protocatechuic acid, 3. (+)-catechin, 4. gentisic acid + p-hydroxybenzoic acid, 5. chlorogenic acid, 6. vanillic acid, 7. caffeic acid, 8. syringic acid, 9. p-coumaric acid, 10. dihydroquercetin, 11. ferulic acid, 12. sinapic acid, 13. o-coumaric acid, 14. cinnamic acid, 15. naringenin. $0.25 \mu \mathrm{g}$ of each standard was injected.

bined and the acetone evaporated in vacuo. The water phase was delipidated with $3 \times 50 \mathrm{ml}$ of petroleum benzin. To increase the yield of free phenolic acids, the water phase was subjected to either acidic or alkaline hydrolysis, as unhydrolysed extracts contain only a small amount of phenolic acids compared to hydrolysed ones. Acidic hydrolysis was performed in $2 \mathrm{~N}-\mathrm{HCl}$ at $100^{\circ} \mathrm{C}$ for $20 \mathrm{~min}$. Alkaline hydrolysis was done in $1 \mathrm{M}-\mathrm{NaOH}$ with $\mathrm{N}_{2}$ bubbling at room temperature over night. Afterwards the $\mathrm{pH}$ was adjusted to 2.0. The phenolic compounds were extracted from the hydrolysed extracts with $3 \times$ $40 \mathrm{ml}$ ethylacetate, evaporated to dryness in vacuo and dissolved in $4 \mathrm{ml} 75 \%(\mathrm{v} / \mathrm{v})$ ethanol. After centrifugation at $9000 \times \mathrm{g}$ for $15 \mathrm{~min}$, the samples were analysed by HPLC.

\subsection{Chromatography}

\subsubsection{High performance liquid chromatography (HPLC)}

Analyses were performed using a Waters Assoc. (Milford, Mass., USA) instrument composed of two Model 6000A solvent delivery systems, a WISP Model 710B sample injector, a
Model 450 variable wavelength detector, a data module and a Model 720 system controller. The separations were carried out on a $\mu$-Bondapak $\mathrm{C}_{18}$ Column, $30 \mathrm{~cm} \times 7.9 \mathrm{~mm}$ (Waters Assoc.), which was eluted isocratically for $10 \mathrm{~min}$ with solvent A (methanol:acetic acid:water, 20:5:75, $\mathrm{v} / \mathrm{v} / \mathrm{v})$, then with a linear gradient to solvent $\mathrm{B}$ (methanol:acetic acid:water, 40:5:55, v/v/v) for $10 \mathrm{~min}$ and maintained at solvent $\mathrm{B}$ for $20 \mathrm{~min}$. The flow rate was $2 \mathrm{ml} \cdot \mathrm{min}^{-1}$ and the elution was monitored spectrophotometrically at $280 \mathrm{~nm}$. Elution volumes for the different phenolic acids and flavonoids are given in Table I. A mixture of 16 standard compounds was used to identify the peaks on the chromatograms (Figure 2). In order to quantify the amounts of phenolic compounds present in grains of the mutants and their mother varieties, known amounts of standards were analysed by HPLC. The reproducibility of the peak areas was within $\pm 2 \%$. Each standard was injected in 3-4 different concentrations. A linear relationsship between peak area and concentration was observed for all standards (Figure 3). The standard curves were used to calculate the amounts of different phenolics on HPLC chromatograms of mutants and wild-types. 


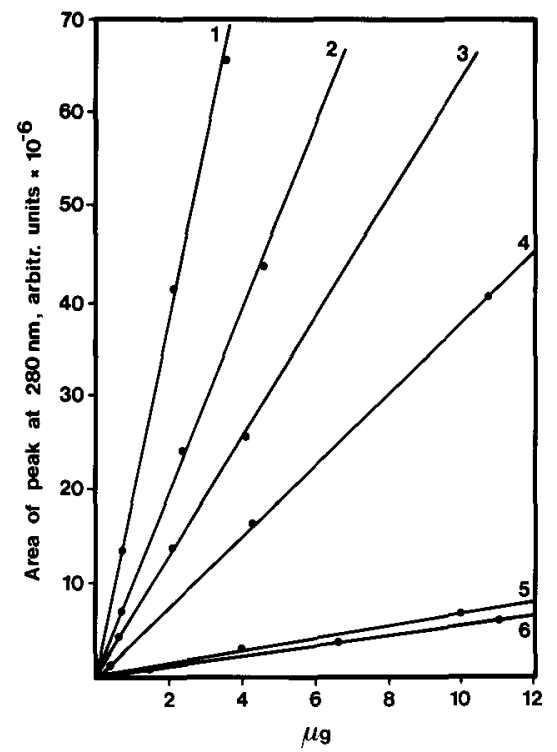

Figure 3. Standard curves for HPLC of selected phenolic compounds. 1. cinnamic acid, 2. dihydroquercetin, 3. syringic acid, 4. gallic acid, 5. (+)-catechin, 6. p-hydroxybenzoic acid.

\subsubsection{Thin layer chromatography (TLC)}

TLC was used to confirm the identity of phenolic compounds separated by HPLC. Fractions, eluted from the HPLC column, were evaporated to dryness in vacuo, dissolved in $1 \mathrm{ml}$ $75 \%$ ethanol $(\mathrm{v} / \mathrm{v})$ and chromatographed together with standard compounds. Separations were performed on Merck (Darmstadt, West Germany) precoated cellulose $F_{254}$ plates $(0.1$ $\mathrm{mm}$ ).

The following solvent systems were used:

(i) CAW (chloroform:acetic acid:water, 10:9:1, $v / v / v)$.

(ii) $\mathrm{BzAW}$ (benzene:acetic acid:water, 125:72:3, $\mathrm{v} / \mathrm{v} / \mathrm{v})$.

(iii) $15 \%$ acetic acid (v/v).

The phenolic compounds were visualized under UV light before and after treatment with $\mathrm{NH}_{3}$ fumes, or by spraying with ethanolic $\mathrm{FeCl}_{2}$ (21), which produces different colours with the different phenolic acids. Rf values, UV fluorescence and colours with $\mathrm{FeCl}_{2}$ are shown in Table I.

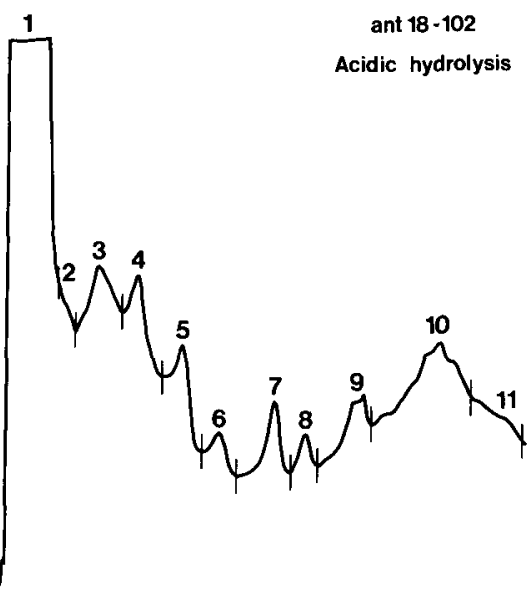

Figure 4. Preparative HPLC analysis of hydrolysed extracts of ant 18-102. 11 fractions were collected and tested for their reaction with ferric ions in alkaline solution according to Jerumanis.

\subsection{The Jerumanis test}

Jerumanis method for measurement of polyphenol content $(1,13)$, is frequently used for measurement of polyphenols in beer and wort. A microscale version of this procedure has been

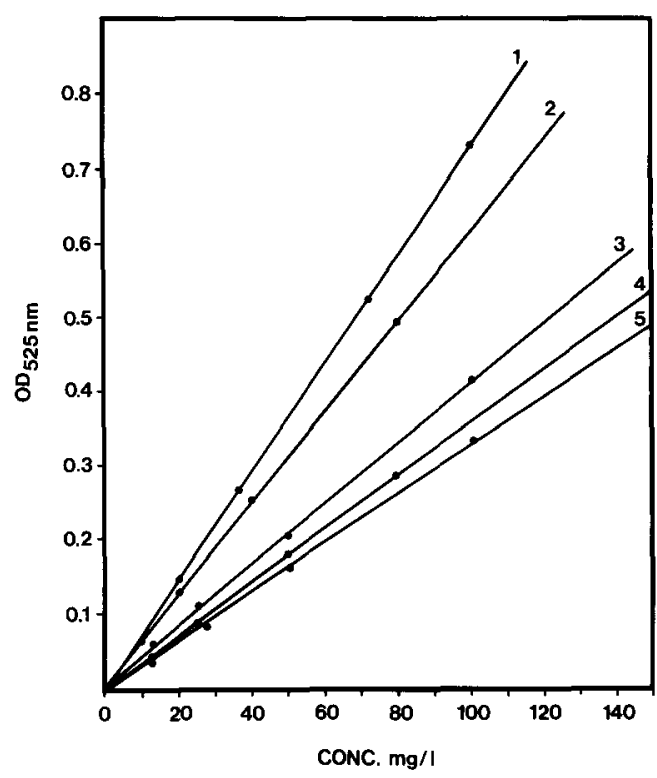

Figure 5. Standard curves of selected phenolic compounds, tested for their reaction with ferric ions according to Jerumanis. 1. gallic acid, 2. protocatechuic acid, 3. chlorogenic acid, 4. (+)-catechin, 5. dihydroquercetin. 

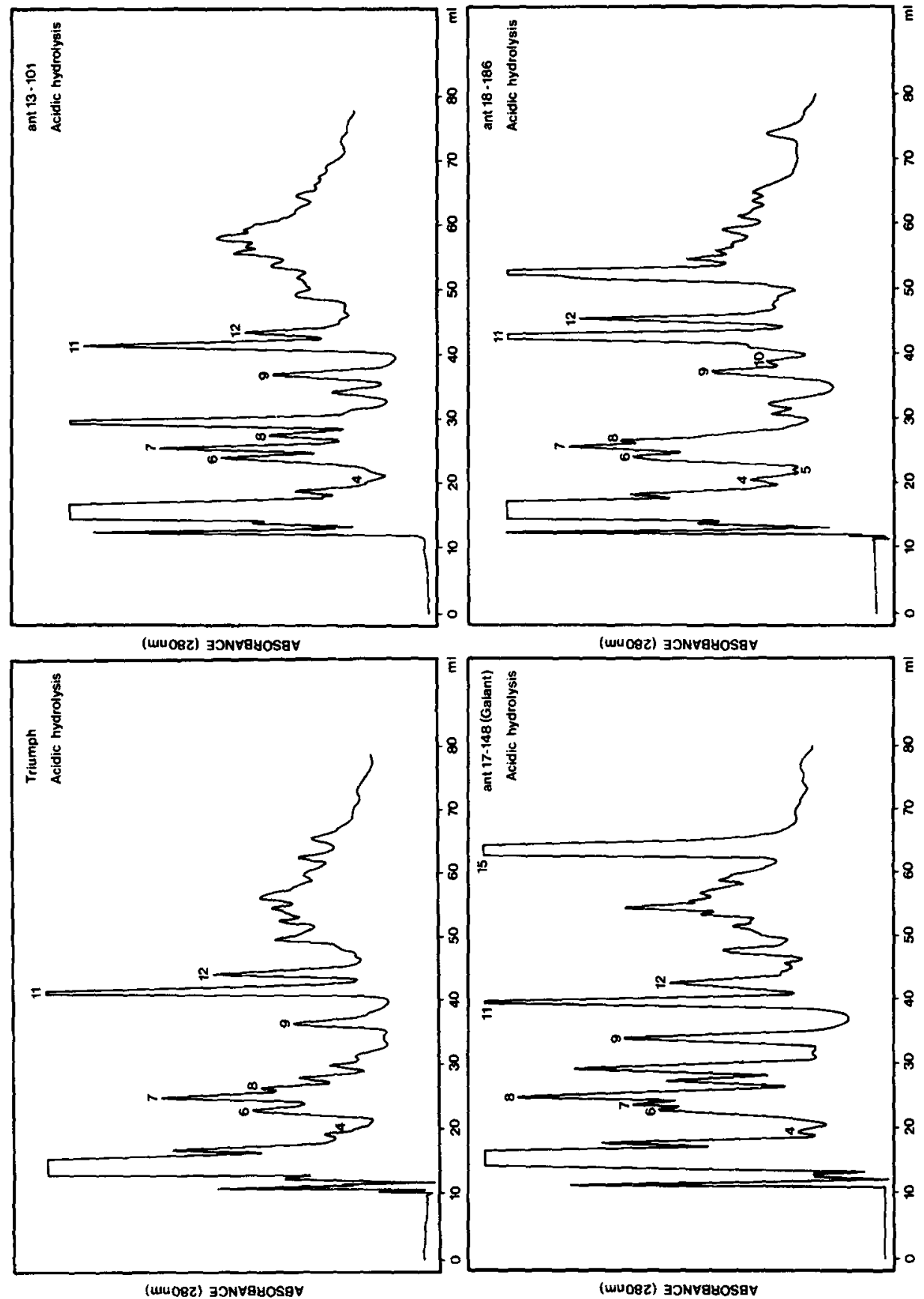


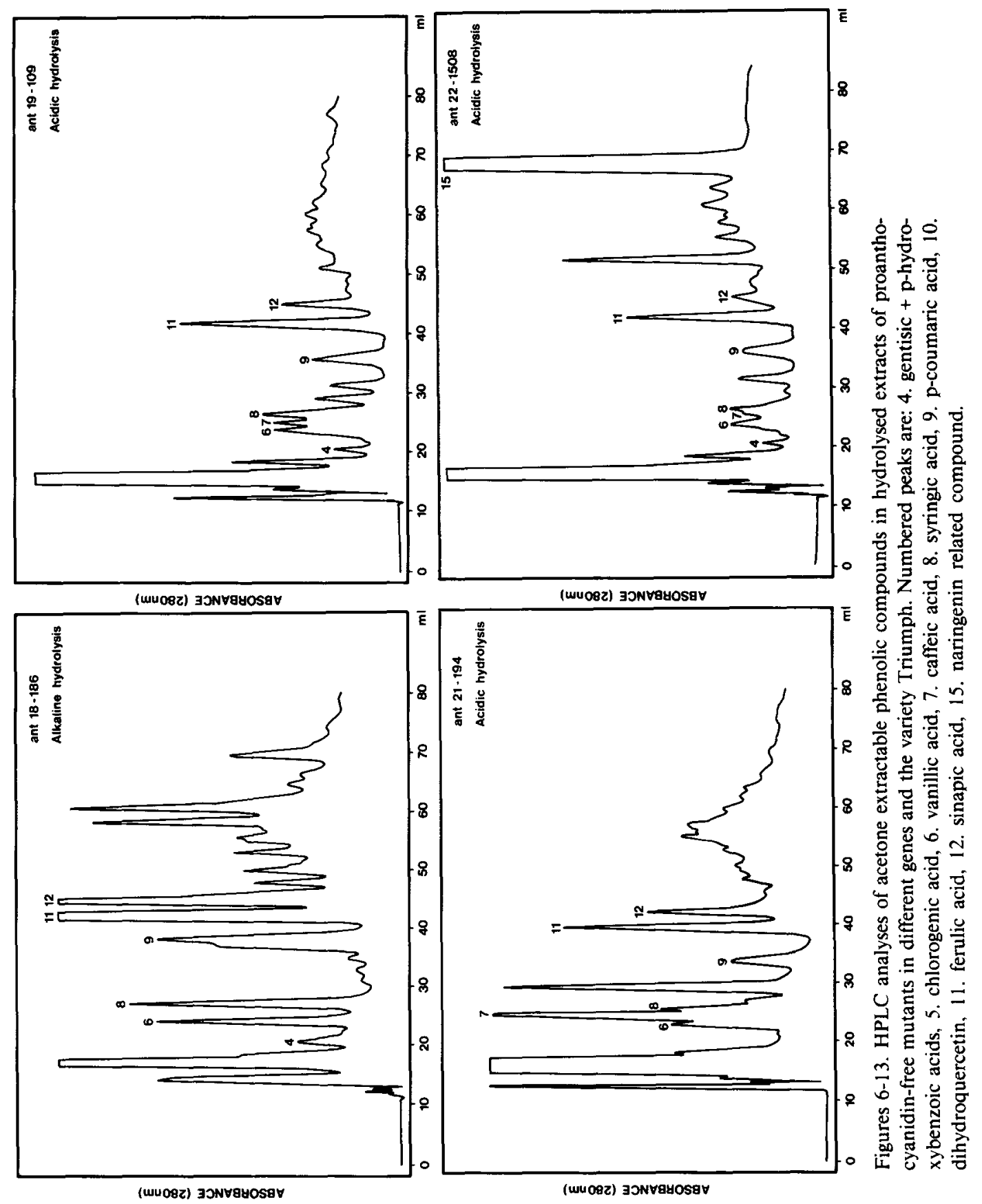


used to test barley extract fractions eluted from the HPLC column. As the method of Jerumanis is very insensitive compared to HPLC analysis, it was necessary to use combined fractions from several separations of the same barley sample. Usually eleven fractions (cf. Figure 4) of around $3-8 \mathrm{ml}$ were collected from six independent HPLC separations, and the corresponding fractions were combined and concentrated in vacuo, and the volume was adjusted to $1.6 \mathrm{ml}$ with $75 \%$ (v/v) ethanol.

$1.6 \mathrm{ml}$ of barley sample was mixed in a cuvette with $1.3 \mathrm{ml}$ of $1 \%(\mathrm{w} / \mathrm{v})$ sodium carboxymethylcellulose with the addition of $0.2 \%(w / v)$ EDTA (CMC/EDTA). $0.1 \mathrm{ml}$ of green ammonium ferric citrate $(3.5 \%, \mathrm{w} / \mathrm{v})$ and $0.1 \mathrm{ml}$ of $\mathrm{NH}_{3}$ $\left(\mathrm{NH}_{3}: \mathrm{H}_{2} \mathrm{O}, 1: 2, \mathrm{v} / \mathrm{v}\right)$ were added. The cuvette was shaken, and after $10 \mathrm{~min}$ the absorbance was measured on a Zeiss PMQ 3 spectrophotometer at $525 \mathrm{~nm}$. A mixture of $1.6 \mathrm{ml} 75 \%$ ethanol, 1.3 $\mathrm{ml} \mathrm{CMC/EDTA,} 0.1 \mathrm{ml}$ ammonium ferric citrate and $0.1 \mathrm{ml} \mathrm{NH}_{3}$ was used as a blank.

All phenolic standards were tested with the procedure of Jerumanis and standard curves were made of the o-diphenols. The optical density (OD) was proportional to the amount of all standards containing adjacent hydroxyl groups, but there was a large difference in absorption at $525 \mathrm{~nm}$ among the different phenolic acids and flavonoids (Figure 5).

\section{RESULTS}

\subsection{Phenolic acids in barley grains}

Phenolic acids were identified by comparison of HPLC retention times with those of authentic compounds, and by TLC co-chromatography in three different solvent systems of standards and concentrated fractions eluted from the HPLC column. (Table 1). There are no qualitative differences in the array of identified phenolic acids present in the grains of wild-type barley and proanthocyanidin-free mutants in the 6 different genes (Figures $6-13$ ).

The following phenolic acids have been identified in acetone extracts after acidic hydrolysis: gentisic acid, p-hydroxybenzoic acid, chlorogenic acid, vanillic acid, caffeic acid, syringic acid, p-coumaric acid, ferulic acid, sinapic acid and cinnamic acid.

In barley extracts after alkaline hydrolysis the following phenolic acids were found: gallic acid, protocatechuic acid, gentisic acid, p-hydroxybenzoic acid, vanillic acid, caffeic acid, syringic acid, p-coumaric acid, ferulic acid and sinapic acid.

Gallic, gentisic and cinnamic acids occur only in trace amounts. The others are more abundant. Gallic acid and protocatechuic acid are the most polar ones of the phenolic acids and are therefore eluted shortly after the void volume on a reversed phase HPLC column. The acid hydrolysed extracts contain contaminating material, which is eluted at void volume, and good separation of the more polar phenolic acids cannot be obtained. However, TLC analyses of these first fractions did not identify gallic and protocatechuic acid either. Caffeic acid and chlorogenic acid are probably broken down in alkaline solution. In some extracts after alkaline hydrolysis trace amounts of caffeic acid are found, but chlorogenic acid has not been identified.

Unhydrolysed extracts contained only small amounts of phenolic acids, indicating that they usually occur in bound form as glucosides or esters. These compounds are not very easily extracted into ethylacetate but remain in the water phase. After hydrolysis the phenolic acids are extracted into the ethylacetate, but the most polar ones are not transferred quantitatively.

In order to investigate the efficiency of the extraction procedure, barley flour samples of ant 17-148 (Galant) were extracted four times with $100 \mathrm{ml} 75 \%$ acetone. Each extraction step was analysed by HPLC, and the three first extractions were found to contain an average of 81,14 and $4 \%$ of the acetone extractable phenolic acids. After four times extraction the barley flour samples were hydrolysed with $100 \mathrm{ml}$ of $2 \mathrm{~N}-\mathrm{HCl}$ at $100{ }^{\circ} \mathrm{C}$ for $30 \mathrm{~min}$, and the hydrolysate reextracted. HPLC analyses of the latter extracts revealed that a large fraction of some of the phenolic acids present in barley grains cannot be extracted with acetone. Only about $10-15 \%$ of ferulic and $p$-coumaric acids are acetone extractable. The rest is probably bound to lignin and cellulose in the cell walls. Direct acidic hydro: lysis of barley flour of Triumph and ant 17-148 
yielded about the same amounts of vanillic, caffeic, syringic and sinapic acids as acetone extraction, but the amounts of p-coumaric and ferulic acids were ten times higher. A considerable amount of gallic acid was also obtained with this method.

\subsection{Flavonoids in barley grains}

Proanthocyanidins and (+)-catechin are the most abundant phenolic compounds in wildtype barley grains. Acidic hydrolysis will degrade the proanthocyanidins with the formation of anthocyanidins and catechin. The conversion is not quantitative, and it appears that catechin is further degraded during hydrolysis, so the amounts of the compound can be greatly underestimated. A sample of unhydrolysed extract of the barley variety Nordal contained $26.9 \mathrm{mg}$ $(+)$-catechin $100 \mathrm{~g}^{-1}$ dry weight according to HPLC analysis. The amount of (+)-catechin in hydrolysed extracts could not be determined by HPLC due to the large UV-absorbing peak at the void volume, but analysis by TLC revealed that only trace amounts of $(+)$-catechin were present, indicating that the acidic hydrolysis had destroyed a large part of the compound. Dihydroquercetin is found in mutants in the gene ant 18 , but only in extracts subjected to acidic hydrolysis. All mutants in the gene ant 17 accumulate a compound, which seems to be related to naringenin. The HPLC retention time is identical to standard naringenin, but TLC analysis of the fraction containing the peak reveals three spots. The $\mathbf{R}_{f}$ value of the main spot differs from the standard in two of the three solvent systems used (Table I). $\lambda$-max. of this compound in $96 \%$ ethanol is $289 \mathrm{~nm}$, which is identical to standard naringenin. The same compound is found in a mutant in the gene ant 22 .

The late eluting part of the HPLC chromatograms of barley grain extracts contain a mumber of small, still unidentified peaks. TLC analyses show, that fractions corresponding to these peaks have $R_{f}$ values and $U V$ fluorescence properties characteristic of flavones. The amounts of these compounds are lower in ant 13 mutants than in mutants in the genes ant 17 and ant 18 and in the mother varieties.

\subsection{Quantitative estimations of phenolic compounds in barley grains}

The amounts of the most abundant phenolic acids, and of dihydroquercetin and the naringenin related compound are presented in Table II for wild-type barley and proanthocyanidin-free mutants in 6 different genes. p-Hydroxybenzoic acid is also one of the more important phenolic acids in barley grains, but it is not separated from gentisic acid by HPLC with the methanol:acetic acid:water solvent system used in the present study. When p-hydroxybenzoic acid and gentisic acid are injected into the HPLC column as single standards their retention times differ by about $10 \mathrm{sec}$, but when injected together in a standard mixture or a barley sample, they elute as one peak (Figure 2). Change of methanol concentration and gradient did not improve the separation.

The sum of the six common phenolic acids in barley grains varied between $5-12 \mathrm{mg} \cdot 100 \mathrm{~g}^{-1}$ of barley (dry weight). The mother varieties contained similar quantities of phenolic acids as most of the mutants. Mutants in the gene ant 18 have a somewhat higher amount of phenolic acids than mutants in the other genes and the mother varieties. With the exception of the ant 18 mutants, the variation in phenolic acid content among mutants in the same gene seems to be as large as that among mutants in different genes, and there is a similar variation in phenolic acid content in the same mutant from year to year.

Mutants in the gene ant 21 accumulate a variable but significantly higher quantity of caffeic acid than mutants in the other genes and wild-types. A sample of ant 21-194, analysed in the spring of 1984 contained $5.2 \mathrm{mg}$ caffeic acid $\cdot 100 \mathrm{~g}^{-1}$ of barley flour (24), whereas another sample of the same mutant analysed in the autumn 1984 contained a much lower amount of caffeic acid, namely $1.77 \mathrm{mg} \cdot 100 \mathrm{~g}^{-1}$ barley flour. Another mutant in the same gene, ant 21-1507, analysed at the same time, contained $1.89 \mathrm{mg}$ caffeic acid $100 \mathrm{~g}^{-1}$ (Table II). A similar big variation is also recorded in the amount of the naringenin related compound accumulated in samples of ant 22-1508 from different years.

The quantities of different phenolic compounds vary also according to the method of 
B. Jende-STRID: Phenolic acids

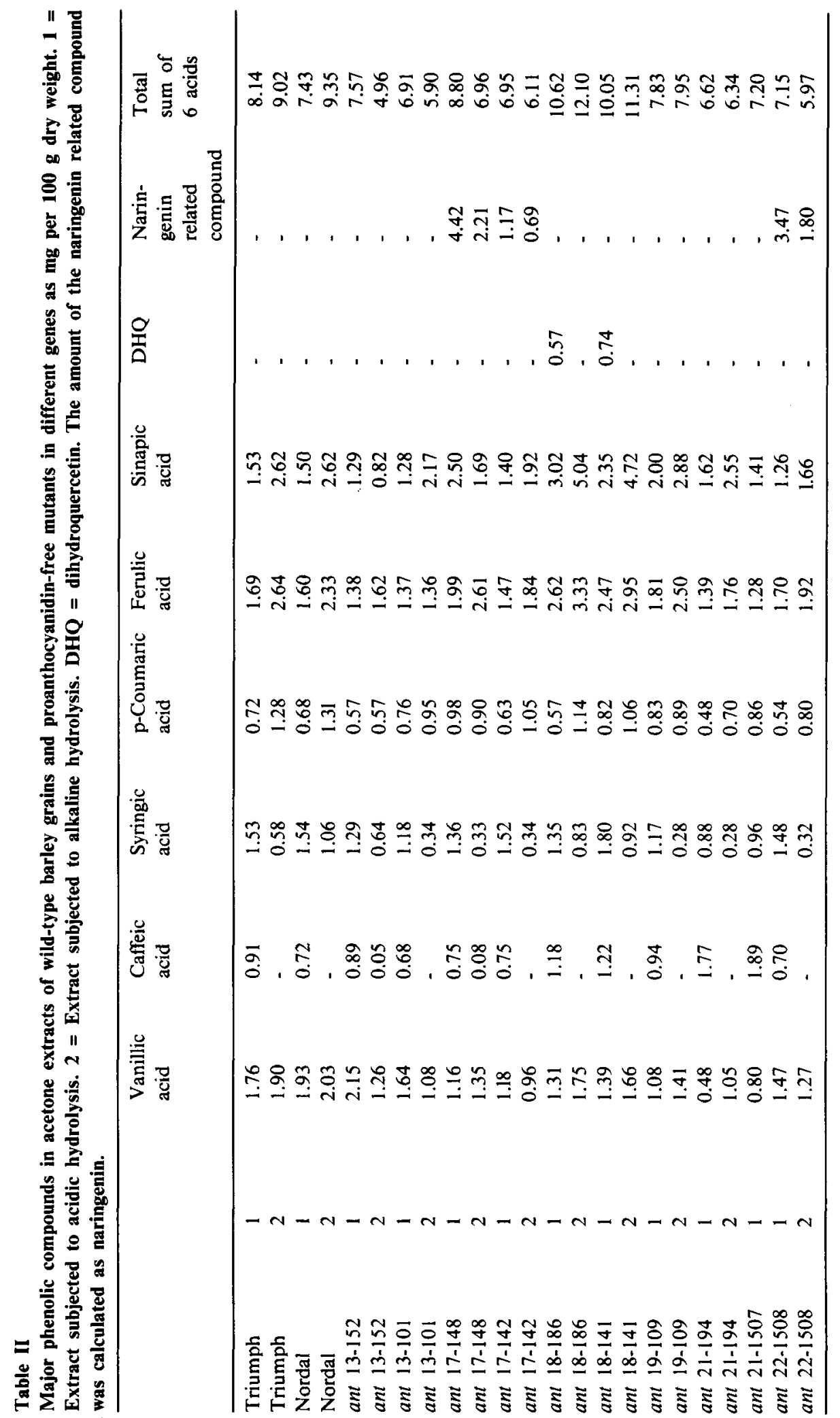


Table III

HPLC fractions according to Figure 4 of extracts from ant 13-152, ant 17-148, ant 18-102 and Nordal. The extracts were tested according to Jerumanis for reaction with ferric ions in alkaline solution. The values are optical densities (OD) at $525 \mathrm{~nm}$ per $10 \mathrm{~g}$ of barley grain.

\begin{tabular}{|c|c|c|c|c|c|}
\hline Fraction no. & $\begin{array}{l}\text { Compounds reacting } \\
\text { with } \mathrm{Fe}^{3+} \text { in } \\
\text { alkaline solution }\end{array}$ & ant $13-152$ & ant $17-148$ & ant $18-102$ & Nordal \\
\hline 1 & $\begin{array}{l}\text { gallic acid } \\
\text { protocatechuic acid } \\
(+) \text {-catechin }\end{array}$ & 0.124 & 0.809 & 0.416 & 2.476 \\
\hline 2 & $\begin{array}{l}\text { (protocatechuic acid) } \\
(+) \text {-catechin }\end{array}$ & 0.091 & 0.327 & 0.336 & 0.305 \\
\hline 3 & chlorogenic acid & - & 0.150 & 0.228 & 0.145 \\
\hline 4 & caffeic acid & 0.040 & 0.106 & 0.178 & 0.212 \\
\hline 5 & - & - & 0.100 & 0.182 & 0.149 \\
\hline 6 & - & 0.040 & 0.027 & 0.240 & 0.022 \\
\hline 7 & dihydroquercetin & - & 0.080 & 0.255 & 0.372 \\
\hline 8 & - & - & 0.117 & 0.286 & 0.172 \\
\hline 9 & $\begin{array}{l}\text { flavone related } \\
\text { compounds }\end{array}$ & - & 0.417 & 0.357 & 0.838 \\
\hline 10 & $\begin{array}{l}\text { flavone related } \\
\text { compounds }\end{array}$ & 0.293 & 1.706 & 1.168 & 2.242 \\
\hline 11 & $\begin{array}{l}\text { flavone related } \\
\text { compounds }\end{array}$ & - & 0.553 & 0.587 & 1.467 \\
\hline
\end{tabular}

hydrolysis used in the preparation of the extracts. Usually the amounts of vanillic, p-coumaric, ferulic and sinapic acids are increased in extracts subjected to alkaline hydrolysis, compared to corresponding extracts after acidic hydrolysis. On the other hand, dihydroquercetin and caffeic acid are absent or occur only in trace amounts, and the quantity of syringic acid is much reduced compared to extracts after acidic hydrolysis. The amount of the naringenin related compound observed in ant 17 mutants after acidic hydrolysis is about twice the amount obtained in the corresponding extracts after alkaline hydrolysis. In solution, naringenin and other flavanones exist in an equilibrium with the corresponding chalcone. In acidic media, the formation of the flavanone is favoured and in alkaline media the chalcone (20). In extracts of standard naringenin, treated in the same way as the ant 17 extracts, part of the naringenin is converted to naringenin chalcone during alkaline hydrolysis.

\subsection{Reactions with ferric ions in alkaline solution}

In the test according to Jerumanis the following equation is used to calculate the amount of polyphenols in beer and wort samples (13): $E_{525} \times 630=$ polyphenols given as $\mathrm{mg} \cdot \mathrm{l}^{-1}$.

The equation is based on a standard curve made up with undefined polyphenols isolated from malt, beer and hops, and it cannot be used to calculate the amounts of phenolic acids and catechin present in individual fractions of barley grain extracts, as it gives polyphenol values about 2-5 times higher than the real value, when applied to known amounts of standards. As some of the 11 fractions collected from hydrolysed barley extracts (Figure 4) could contain more than one o-diphenol, no attempt was made to calculate the quantity of each one. Instead the optical densities (OD) of the different fractions from the wild-type and three mutants were compared (Table III).

In all barley extracts the first and the last three fractions had the highest OD. The first fraction 
of the hydrolysed wild-type extracts contains some $(+)$-catechin and shows a higher OD than that of the ant mutants. In addition to (+)-catechin, gallic and protocatechuic acids are eluted in this fraction. There might be some protocatechuic acid and $(+)$-catechin eluted in fraction 2 as well. In unhydrolysed wild-type extracts the proanthocyanidins are eluted in the first fraction. The last fractions, 9-11, have the highest OD in extracts from the proanthocyanidinfree ant 17 and ant 18 mutants as well as in the hydrolysed extracts from the mother varieties. When fractions 9-11 of ant 13-152 were tested, their OD was significantly lower than in corresponding fractions of ant 17 and ant 18 mutants and the wild-types. In fractions 9-11 cinnamic acid is the only compound fully identified so far, and it does not react with ferric ions in alkaline solution. Fractions 9-11 contain the flavone related compounds mentioned earlier, and flavones with two adjacent hydroxyl groups in the aromatic rings do react with ferric ions under these conditions. These compounds might be responsible for the high OD obtained in the latter fractions.

\section{DISCUSSION}

In 1963 URION and co-workers (21) used TLC to separate and identify phenolic acids in hydrolysed extracts of grains of the barley variety Violette de Guimalaye. The following acids were found: protocatechuic acid, gentisic acid, p-hydroxybenzoic acid, chlorogenic acid, vanillic acid, caffeic acid, syringic acid, ferulic acid, isoferulic acid and sinapic acid (21). Later studies on the phenolic acid composition of barley, malt, wort, beer and beer hazes, employing the HPLC technique, have given similar results (4, 17, 19, 22). Gallic acid, gentisic acid and cinnamic acid are not reported by all workers, however. In addition, kojic acid has been found in wort and beer by QURESHI et al. (19) and in wort by WACKERBAUER et al. (22).

While different workers agree on the qualitative composition of phenolic acids in brewing materials, the quantitative determinations of phenolic compounds have given very different results. For instance, according to WACKERBAUER et al. (22), gentisic acid is the most important phenolic acid in barley grains, and an amount of $11.6 \mathrm{mg} \cdot 100 \mathrm{~g}^{-1}$ dry weight is reported. MCMurRough et al. (17) failed to report it, and in the present investigation only trace amounts were found. MCMURROUGH et al. measured the phenolic acid content in grains of ant 13-13 and the variety Emma. The amounts of major phenolic acids were $6.5 \mathrm{mg} \cdot 100 \mathrm{~g}^{-1}$ and $1.5 \mathrm{mg} \cdot 100 \mathrm{~g}^{-1}$, respectively. In the present study the same amount of phenolic acids was obtained in ant 13 mutants, but the wild-type barley varieties also contained between $7-10 \mathrm{mg}$ of major phenolic acids $\cdot 100 \mathrm{~g}^{-1}$ dry matter (Table II). Emma barley might be especially low in phenolic acid content.

The amount of phenolic acids in barley grains is low compared to the amount of proanthocyanidins and catechin. Typically wild-type barley varieties contain around 130-200 mg proanthocyanidin and catechin $100 \mathrm{~g}^{-1}$ dry weight as measured by Harris and Ricketts' method and by HPLC $(11,23)$, and the total amount of acetone extractable phenolic acids in wild-type barley is around $10-20 \mathrm{mg} \cdot 100 \mathrm{~g}^{-1}$, i.e. ca. $10 \%$ of the amount of the flavanoids. This result is in agreement with other investigations, which have concluded that simple phenolic acids cannot be considered as significant flavour constituents of beer or major components of beer haze $(4,17)$.

Only o-diphenols give rise to a coloured complex with ferric ions under the conditions used in the Jerumanis method for measurement of total polyphenols in beer and wort (13). This means that only a few of the phenolic acids present in barley grains, namely gallic acid, protocatechuic acid, chlorogenic acid and caffeic acid can contribute to the total polyphenol content as measured according to this procedure. As the amount of these acids is small compared to the total amount of proanthocyanidin and catechin in wild-type barley, their presence in ant 17 and ant 18 mutants cannot explain the high amount of polyphenols estimated in beers made from these mutants. Dihydroquercetin reacts with ferric ions in alkaline solution, but the dihydroquercetin content in the ant 18 mutants, while significant, is also very low compared to the amount of proanthocyanidin in wild-type barley. 
FRÖST, HARBORNE and KING have identified a great number of flavoneglucosides and C-glucosyl flavones in leaves of different barley varieties (9). These compounds react with ferric ions. Also quercetin, which is present in beer and hops, gives a coloured complex with ferric ions in alkaline solution. None of these compounds have so far been identified in barley grains, but it is likely that they occur, and that the flavone related compounds found in the late parts of the HPLC chromatograms indeed are flavones or C-glucosylflavones. The amount of these compounds is lower in ant 13 mutants than in ant 17 and ant 18 mutants and wildtypes, and so is the polyphenol content as measured according to the procedure of Jerumanis. Thus, the high polyphenol values obtained in beers brewed from proanthocyanidinfree lines with mutations in the genes ant 17 and ant 18, are probably due to the presence in the grains of other flavonoids than proanthocyanidins and catechin.

\section{ACKNOWLEDGEMENTS}

Professor DITER VON WETTSTEIN is thanked for reviewing the manuscript. Thanks are also due to cand. scient. K.N. KRISTIANSEN for helpful discussions.

\section{REFERENCES}

1. Analytica-EBC, Analysis Committee of European Brewery Convention. T.-M. Enari ed. Schweizer Braueri-Rundschau, 3rd ed. Zürich, 120 pp (19751983)

2. Brandon, M.J., L.Y. Foo, J.L. Porter \& P.M. MEREDITH: Proanthocyanidins of barley and sorghum: Composition as a function of maturity of barley ears. Phytochemistry 21, 2953-2957 (1982)

3. DADIC, M. \& J.E.A. vaN GHELUwE: The role of polyphenols and non-volatiles in beer quality. MBAA Tech. Quarterly 10, 69-73 (1973)

4. Dadic, M. \& G. BelleaU: Beer hazes I. Isolation and preliminary analysis of phenolic and carbohydrate components. ASBC Journal 38, 145-158 (1980)

5. Delcour. J.A., M.M. Vandenberghe, P. DONDEYNe, E.L. Schrevens, J. WiJnhoven, \& E. MOERMAN: Flavour and haze stability differences in unhopped and hopped all-malt pilsner beers brewed with proanthocyanidin-free and with regular malt. J. Inst. Brew. 90, 67-72 (1984)

6. Delcour, J.A., M.M. Schoeters, R.W. MeYSMAN,P.DONDEYNE\& E. MOERMAN: The intrinsic influence of catechins and proanthocyanidins on beer haze formation. J. Inst. Brew. 90, 381-384 (1984)

7. Erdal, K., B. Ahrenst-Larsen. \& B. JendeSTRID: Use of proanthocyanidin-free barley in beer brewing. In Cereals for Food and Beverages. G.E. Inglett \& L. Munck eds. Academic Press, New York 365-379 (1980)

8. Erdal, K., H. Outtrup \& B. Ahrenst-Larsen: The role of proanthocyanidins in beer flavour and flavour stability. Proc. Europ. Brewery Conv. Congr., London 1983, 557-569 (1983)

9. Fröst. S., J.B. Harborne \& L. KING: Identification of flavonoids in five chemical races of cultivated barley. Hereditas 85, 163-168, (1977)

10. Harborne, J.B. \& N.W. SimmondS: The natural distribution of phenolic aglycones. In Biochemistry of Phenolic Compounds. J.B. Harborne ed. Academic Press, London 78-127 (1964)

11. Jende-Strid, B. \& B.L. Møller: Analysis of proanthocyanidins in wild-type and mutant barley (Hordeum vulgare L.). Carlsberg Res. Commun. 46. 53-64 (1981)

12. Jende-STRID, B.: Anthocyanin genes. Barley Genetics Newsl. 14, 76-79 (1984)

13. Jerumanis, J.: Simplification et amélioration de la méthode de dosage de polyphenols toteaux en brasserie. Bull Ass. Anc. Etud. Ec. Super. Brass. Univ. Louvain 64, 223-240 (1968)

14. Jerumanis, J.: Separation et identification de flavonoides par chromatographie liquide a haute performance (HPLC). Proc. Europ. Brewery Conv. Congr., Berlin 1979, 309-319 (1979)

15. KRISTIANSEN, K.N.: Biosynthesis of proanthocyanidins in barley: Genetic control of the conversion of dihydroquercetin to catechin and procyanidins. Carlsberg Res. Commun. 49, 503-524 (1984)

16. McFarlane, W.D., E. Wye \& H.L. Grant: Studies on the flavonoid compounds in beer. Proc. Europ. Brewery Conv. Congr., Baden-Baden 1955, 298-308 (1955)

17. McMurrough, I., G.P. Roche \& K.G. Cleary: Phenolic acids in beers and worts. J. Inst. Brew. 90, 181-187 (1984)

18. OutTrup, H.\& K. Erdal: Haze forming potential of proanthocyanidins. Proc. Europ. Brewery Conv. Congr., London 1983, 307-314 (1983)

19. Qureshi, A., W.C. Burger \& N. Prentice: Quantitation of potential flavouring compounds in worts and beers by HPLC. ASBC Journal 37, 153-160 (1979) 
20. SESHAdRI, T.R.: Interconversions of flavonoid compounds. In The Chemistry of Flavonoid Compounds. T.A. Geisman ed. The MacMillan Company, New York, 156-196 (1962)

21. URION, E., M.MeTChE \& J.P. HaluK: Bestimmung der Phenolsäuren der Gerste mittels PolyamidDünnschicht-Chromatographie. Brauwissenschaften 16, 211-215 (1963)

22. Wackerbauer, K.. P. KRAmer \& J. Siepert: Phenolische Aromastoffe in Bier. Brauwelt 15, 618626 (1982)

Accepted by: H. KLenOw, E. LuND and S.O. ANDERSEN
23. Wettstein, D. von, J. LARSEn, B. Jende-Strid, B. AHRENST-LARSEN, J.A. SøRENSEN \& K. ERDAL: Proanthocyanidinfreie Braugersten. Brauwelt 121 , 760-767 (1981)

24. Wettstein, D. von, R.A. Nilan, B. AhrenstLarsen, K. Erdal, J. IngVersen, B. JendeStrid, K. Kristiansen, J. Larsen, H. OUtTRuP, \& S.E. ULLRICH: Proanthocyanidin-free barley for brewing: Progress in breeding for high yield and research tool in polyphenol chemistry. MBAA Tech. Quarterly. 22, in press (1985) 